\title{
Cursing \\ EFFECTIVENESS OF MIND MAPPING VS LECTURE METHOD ON LEARNING REGARDING PHYSIOLOGICAL CHANGES DURING PREGNANCY AMONG NURSING STUDENTS IN OJASWINI COLLEGE OF NURSING DAMOH.
}

\section{Prof Sudharani B Banappagoudar}

\author{
Academic Head, Rama University Faculty Of Nursing, Kanpur.
}

ABSTRACT BACKGROUND OF THE STUDY: The several teaching-learning methods used in education are lecture, demonstration, simulation, micro teaching, field trip, computer oriented instruction, socio drama, programmed instruction, and socialized classroom method. Mind mapping is a newer method of teaching, in which a main idea will be in the center from which sub branches arise. Lecture method is a traditional method of teaching. PURPOSE: The purpose of the study was to find out the effective method of teaching to improve the learning ability of nursing students.Physiological changes during pregnancy was the topic selected to assess the learning because it is an important and vast topic in obstetrics and gynaecology. AIM: The aim of this study was to compare the effectiveness of mind mapping and lecture method on learning regarding physiological changes during pregnancy. METHOD: A quantitative approach with true experimental pre-test post test design was used for the study. The subjects consisted of 60 nursing students. The subjects were selected using simple random sampling technique. The data was collected by administering a structured questionnaire regarding physiological changes during pregnancy. The researcher gave teaching to Group 1 using mind map and Group 2 using lecture method. A post test was conducted on the seventh day using the same structured questionnaire. RESULTS: The collected data was analyzed using descriptive and inferential statistics. The pre and post test learning scores on mind mapping and lecture method were compared by using paired 't'test. In Group-1, mean pre and post test learning scores were $23.75 \pm 2.62$ and $31.2 \pm 3.37$ respectively, whereas in Group-2 it was $22.13 \pm 2.33$ and $29.73 \pm 3.98$ respectively. The calculated paired't' values of group- 1 and group- 2 were 7.306 and 10.15 respectively ( $29=1.70, \mathrm{P}<0.05)$. It concluded that both mind mapping and lecture method were effective in increasing learning score on physiological changes during pregnancy among nursing students. INTERPRETATION AND CONCLUSION: The study findings showed that both mind mapping and lecture method were equally effective in improving the learning scores on physiological changes during pregnancy among third year B.Sc nursing students. No significant association was found between the pre-test learning scores and the selected demographic variables.

\section{KEYWORDS : Learning, Nursing Students, Physiological Changes During Pregnancy, Mind Map, Lecture Method.} \section{INTRODUCTION}

According to the Rig-Veda, "Education is the source of all illumination."Education is as old as the human race. It is closely bound with the intellectual, economic, cultural, emotional, and social life of the human race. The word education is derived from the Latin word "educere" which means to lead out, to bring up, to train or to mould".

According to Mahatma Gandhi, "Education is the all round drawing out of the best in child and man's body, mind and spirit." There are several teaching-learning methods used in education. They are: lecture, demonstration, simulation, micro teaching, field trip, computer assisted instruction, project method, laboratory method, socio drama, programmed instruction, socialized classroom method ${ }^{2}$.

The 'Laws of Mind Mapping' were originally devised by Tony Buzan when he codified the use of imagery, colour and association and coined the phrase 'Mind Mapping ${ }^{13}$. A mind map is a graphic organizer in which the major categories radiate from a central image and lesser categories are portrayed as branches of larger branches. It can be used to generate ideas, take notes, develop concepts and ideas, and improve memory ${ }^{4}$.It is a diagram used to visually outline information. A mind map is often created around a single word or text, placed in the center, to which associated ideas, words and concepts are added.

Mind maps have many applications in personal, family, educational, and business situations, including note taking, brainstorming (wherein ideas are inserted into the map radically around the center node, without the implicit prioritization that comes from hierarchy or sequential arrangements and wherein grouping and organizing is reserved for later stages), summarizing, as a mnemonic technique or to sort out a complicated idea. Mind maps are also promoted as a way to collaborate in color pen creativity sessions. ${ }^{5}$

Mind maps can be used for problem solving, outline/framework design, structure/relationship representations, anonymous collaboration, individual expression of creativity, condensing material into a concise and memorable format, team building or synergy creating activity, enhancing work morale.

Lecture method is the oldest teaching method given by philosophy of idealism. It refers to the teaching procedure involved in clarification or explanation of the students of some major idea. Teacher is more active and students are passive. It is used to motivate, clarify, expand and, review the information.

\section{METHODOLOGY}

Formal written permission was obtained from the Management of Ojaswini College of Nursing, Damoh, to conduct the study. The data collection was done in the month of October 2016. The subjects were gathered as per the fixed schedule in a classroom and made comfortable. The purpose of the study was explained to them and informed consent was obtained. Confidentiality was assured to all the subjects and their co-operation was sought throughout the process of data collection. Sixty subjects who fulfilled the inclusion criteria were selected by simple random sampling and were randomly assigned to Group1 and Group 2. On the first day pre test was given to group 1 $(n=30)$ followed by teaching on physiological changes during pregnancy using mind mapping. The whole procedure took a period of three hours. On the next day, Group 2 was given the pre-test followed by teaching physiological changes during pregnancy using lecture method. This took a total period of three hours. Both groups were taught on different days.

The data was decided to be analyzed by using descriptive and inferential statistics. To compute the data, a master data sheet will be prepared by the researcher. The researcher will analyze the data based on the objectives and the hypothesis of the study using descriptive and inferential statistics.

- Demographic variables would be analyzed using frequency and percentage

- Data on structured questionnaire would be analyzed using descriptive and inferential statistics.

- Paired 't' test will be used to find significant difference within the experimental groups

- Comparison of mind mapping and lecture method will be done by unpaired ' $t$ ' test

- Chi-square test will be used to find the association between pre test score and selected demographic variables

\section{RESULTS}

Regarding socio-demographic characteristics, it was found that highest number of subjects $16(53.33 \%)$ were in the age group of $20-22$ years and other $14(46.66 \%)$ were in the age group of $20-22$ years respectively. The subjects in lecture method group and majority $(96.66 \%)$ of subjects in mind mapping group were females. Only 3.33 $\%$ of subjects were males and they belonged to mind mapping group. All the subjects $(100 \%)$ in mind mapping group and majority of subjects in lecture method group $(93.33 \%)$ have scored between 50 $75 \%$ marks in the previous university exam. Only a small percentage 
(6.66\%) of subjects have scored less than $50 \%$ marks in the previous university examination and they belonged to lecture method group.

The comparison of pre-test and post test learning scores of mind mapping and lecture method group. In mind mapping group the post test learning score $(31.2 \pm 3.37)$ which is $57.7 \%$ was higher than pretest mean learning score $(23.75 \pm 2.62)$ which is $43.9 \%$ whereas in lecture method group, the post test mean learning score $(29.73 \pm 3.98)$ which is $55 \%$ was higher than the pre-test mean learning score $(22.13$ \pm 2.33 ) which is $40.9 \%$. This indicates both mind mapping and lecture method were increasing the learning scores of nursing students.

System wise post test learning scores of mind mapping and lecture method regarding physiological changes during pregnancy. The highest mean percentage has been observed in gastrointestinal system $(74.3 \%)$ in mind mapping and highest in lecture method was in respiratory system $(66.5 \%)$. The least mean percentage in mind mapping was in weight gain $(42.5 \%)$ and $(25 \%)$ in lecture method group. The gastrointestinal system has scored the highest actual mean percentage difference $(29 \%)$ and reproductive system has scored the lowest $(-0.83 \%)$ mean percentage difference.

pre and post test learning scores of mind mapping and lecture method regarding physiological changes during pregnancy. It was found that majority of subjects in pre-test ie. $23(77 \%)$ and $27(90 \%)$ obtained poor score $(<27)$ mind mapping and lecture group respectively. However, during post test $15(50 \%)$ obtained good score (33-43) in mind mapping group whereas in lecture method group each $12(40 \%)$ obtained average (27-32) and poor score $(<27)$ respectively and no one has obtained excellent in both groups.

The comparison of pre and post test learning score of mind mapping show that the highest score ranged between 21 to 24 during the pre-test whereas during the post test the highest score was between 33 to 36.The median plotted on the graph shows that the pre-test mean and median scores were 23.75 and 23 respectively. However, during the post test mean and median score values were 31.2 and 32.5 respectively. Thus, it reveals effectiveness of the mind mapping on learning regarding physiological changes during pregnancy.

The comparison of pre and post test learning score of lecture method show that the highest scores ranged between 21 to 24 during the pretest whereas during the post-test the highest scores were between 27 to 30 . The median plotted on the graph shows that the pre-test mean and median scores were 22.13 and 22.5 respectively. However, during the post-test mean and median score values were 29.73 and 29 , respectively. Thus, it reveals effectiveness of the lecture method on learning regarding physiological changes during pregnancy

paired't' value of learning scores among mind mapping and lecture method groups. In mind mapping, the post test mean learning score(31.2 \pm 3.37$)$ was higher than pre-test mean learning score $(23.75 \pm 2.62)$

The computed ' $t$ ' value of learning score is greater than the table value, $\mathrm{t}=7.306(\mathrm{t} 29=1.70, \mathrm{p}<0.05)$.

In lecture method group, the post test mean learning score $(29.73 \pm$ $3.98)$ was higher than pre-test mean learning score $(22.13 \pm 2.33)$. The computed ' $t$ ' value of learning score is greater than the table value, $\mathrm{t}=10.15(\mathrm{t} 29=1.70, \mathrm{p}<0.05)$.

On the basis of this, $\mathrm{H} 01$ and $\mathrm{H} 02$ hypotheses are rejected and research hypotheses $\mathrm{H} 1$ and $\mathrm{H} 2$ are accepted. This indicates that mind mapping and lecture method can significantly increase the learning score of nursing students.

There was no significant association between pre-test scores with demographic variables such as age $(\chi 2=0.334)$, gender $(\chi 2=0.044)$, total marks $(\%)$ scored in previous university exam $(\chi 2=0.414)$ in mind mapping group whereas in lecture group also there was no significant association between pre-test scores with demographic variables such as age $(\chi 2=0.17)$ and total marks $(\%)$ scored in previous university exam $(\chi 2=1.14)$. The calculated $\chi 2$ value of learning scores were lesser than the table value $(\chi 2=1.7, \mathrm{p}>0.05)$. So null hypothesis $\mathrm{H} 04$ was accepted and research hypothesis $\mathrm{H} 4$ was rejected. Hence, it was concluded that there was no significant association between pretest learning scores and demographic variables of 3rd year B.Sc nursing students.

\section{DISCUSSION}

Majority (51.6\%) of the subjects were in the age group of 20-22 years, whereas only $48.3 \%$ of the subjects were in the age group 22 years. Majority $(98.3 \%)$ of the subjects were females whereas only one (1.6\%) was male.

The present study findings were supported by an experimental study which was conducted to assess the effectiveness of STP on electrocardiogram among B.Sc nursing students at Raichur. Among fifty two participants, majority was in the age group of 21-22 years $(86.5 \%)$ and majority $(90.4 \%)$ of students was females ${ }^{7}$. Majority $(96.6 \%)$ of the subjects have sco red $50-75 \%$ marks, whereas, only $3.3 \%$ of subjects have scored.

The present findings are supported by the following studies: A study was conducted on effectiveness of sex and method of teaching on academic achievement for science teaching in Gujarat. The sample consisted of 88 boys and 113 girls of 8th class. Teaching methods namely program learning and demonstration method considered as dependent variables and two levels of sex (boys and girls) as independent variables. The results revealed that there was no effect of sex on academic achievement, where as the methods of teaching had effect on academic achievement ${ }^{8}$. A study on pre-test and post test on the topic of evolution by natural selection were administered to students in a college non-majors' biology course. Although students had taken an average of 1.9 years of previous biology courses, performance on the pre-test was uniformly low. The results revealed that there was no relationship between the amount of previous biology taken and either pre-test or posttest performance?.

\section{CONCLUSION}

Mind mapping was an effective method in increasing learning score on physiological changes during pregnancy. Lecture method was effective in increasing the learning score on physiological changes during pregnancy. The study concluded that both the methods were equally effective in increasing the learning scores of nursing students by comparing post test learning scores of mind mapping and lecture method groups. The present study enabled to identify different teaching methods which are effective in teaching. The findings of the study have implications for nursing practice, nursing education, nursing administration, and nursing research.

\section{Recommendations}

On the basis of the finding of the study the following recommendations have been made:

1. A study can be done to compare with other teaching learning methods.

2. The study may be repeated by taking a larger sample.

3. A similar study may be conducted with different teaching strategies.

4. A similar study can be done in other professional areas.

\section{REFERENCES}

1. Basavanthappa BT. Nursing Education.1 1sted. New Delhi: Jaypee publication; 2003

2. Neeraja KP. Textbook of Nursing Education. 1 sted. NewDelhi: Jaypee publication; 2003. Illumine training, better brains for better business [online]. [cited 2012 oct 10]; Available from URL:http://www.mind-mapping.co.uk

4. Al-jarf R. Teaching spelling skills with a mind mapping software. Asian EFL Journal 2011 July; 3:4.[online]. Available from: URL:http://www.asian-efljournal.com/PTA/ Volume-53-raj.pdf 5. Mind map. [online]. Wikipedia. [cited 2012 dec 4]; Available from URL:http://en.

6. Answers. [online]. Wikipedia. [cited 2012 nov 23]; Available from : URL :http://www.wiki.answers.com

7. Rani SS.A study to assess the effectiveness of STP on electrocardiogram among final year B.Sc nursing students, Raichur ;2000

8. Ghetiya SM.A study of effectiveness of sex and methods of teaching on academic achievement for science teaching, IndPsy Review 2000;54(1-2):40-2.

9. Anderson CW, Bishop BA. Student conceptions of natural selection and its role in evolution. Journal of Research in Science Teaching 1990;27( 5): 415-27 